\title{
Air outside the airways: an unusual complication of asthma
}

\author{
Nitesh Gupta, Mahendran A J, Shibdas Chakrabarti, Sumita Agrawal
}

VMMC and Safdarjung Hospital, New Delhi, India, New Delhi, India

A 19-year-old male, non-smoker with asthma since 8 years presented with sudden onset dyspnea over three days alongwith swelling over the body beginning from chest and extending to face since one day. No history of chest pain, vomiting, weight lifting, rapid ascent or descent of altitude. His asthma was well controlled on long acting beta-2-agonists and inhaled corticosteroids.

On examination, patient was afebrile, respiratory rate $-42 / \mathrm{min}$, regular pulse $-145 \mathrm{bpm}$ and blood pressure $-101 / 68 \mathrm{~mm} \mathrm{Hg}$. His $\mathrm{SpO}_{2}$ at room air - 78\%. Blood gas analysis: $\mathrm{pH}-7.32, \mathrm{pCO}_{2}-55 \mathrm{~mm}$ $\mathrm{Hg}, \mathrm{pO}_{2}-50 \mathrm{~mm} \mathrm{Hg}$ and $\mathrm{HCO}_{3}-24.5 \mathrm{mmol} / \mathrm{L}$. Respiratory movements were bilaterally reduced in all areas. Crepitations were present in bilateral hemithoraces. Vesicular breath sounds of reduced intensity were heard bilaterally. Patient`s chest roentgenogram showed bilateral pneumothorax $(2 \mathrm{~cm}$ on right; $1 \mathrm{~cm}$ on left), pneumomediastinum and subcutaneous emphysema all over the chest wall extending upto neck (Figure 1A).

Bilateral intercostal tube thoracostomy (ICT) was done through the $4^{\text {th }}$ intercostal space in the midaxillay line (Figure 1B). CECT (Contrast enhanced Computed Tomography) chest was done showed no cysts, bullae or emphysema. Trachea, major bronchus and esophagus were normal (Figure 1C). On ${ }^{\text {rd }}$ day, complete lung expansion was present with no air leak in tubes. After clamping tubes alternatively, there was no recurrence of pneumothorax. Subsequently pleurodesis with doxycycline was done and tubes were removed.

Pneumothorax can have varied presentation ranging from being asymptomatic to severe life threatening illness depending upon the aetiology and underlying cardioplulmonary reserve [1].

Primary spontaneous pneumothorax (PSP) is generally seen in tall, thin, men with no otherwise underlying pathology and the most likely cause being rupture of subpleural blebs. Secondary spontaneous pneumothorax (SSP) most commonly occurs in cases of chronic obstructive pulmonary diseases. Others being suppurative lung diseases, malignant lung diseases, interstitial lung diseases, lymphagioleiolyomatosis, histiocytosis X, infections, acute respiratory distress syndrome, catamenial pneumothorax [1].

Asthma as a cause of spontaneous pneumothorax is a very rare presentation. The various causes of pneumothorax in reported cases of asthma were subpleural blebs, intubation, central line insertion, diffuse pulmonary ossification [2-10], occupational exposure to aluminium [11] and metal use to SSP [12] and cases of Boerhaave's syndrome [13, 14].

Menga et al. in their series of 46 patients patients with pneumothorax had found alpha-1 antitrypsin (AAT) deficiency in 8 (17.3\%) of them [15]. The recommendations of the Polish Respiratory Society for Standards for Diagnosis and Care of Patients with AAT Deficiency mentions one of the main indications for diagnosing alpha-1 antitrypsin deficiency as bronchial asthma [16]. Our patient's AAT levels were normal (1.72 g/L).

Immediate management in cases of bilateral pneumothoraces is bilateral chest drain insertion with subsequent intervention to prevent recurrence [17]. This can be done using VATS or open thoracotomy with bullectomy, surgical pleurectomy, pleural abrasion and talc pleurodesis. We did bilateral pleurodesis for our patient.

This case report underlines the need to evaluate cases of asthma presenting in acute exacerbation for pneumothorax and the need to evaluate the underlying cause for definitive management.

Address for correspondence: Sumita Agrawal, Department of Pulmonary Medicine, Medipulse Hospital, Jodhpur 342005, India; e-mail: doc.sumitaagrawal@gmail.com

DOI: 10.5603/ARM.2019.0026

Received: 01.04.2019

Copyright (C) 2019 PTChP

ISSN 2451-4934

Conflict of interest: none declared 

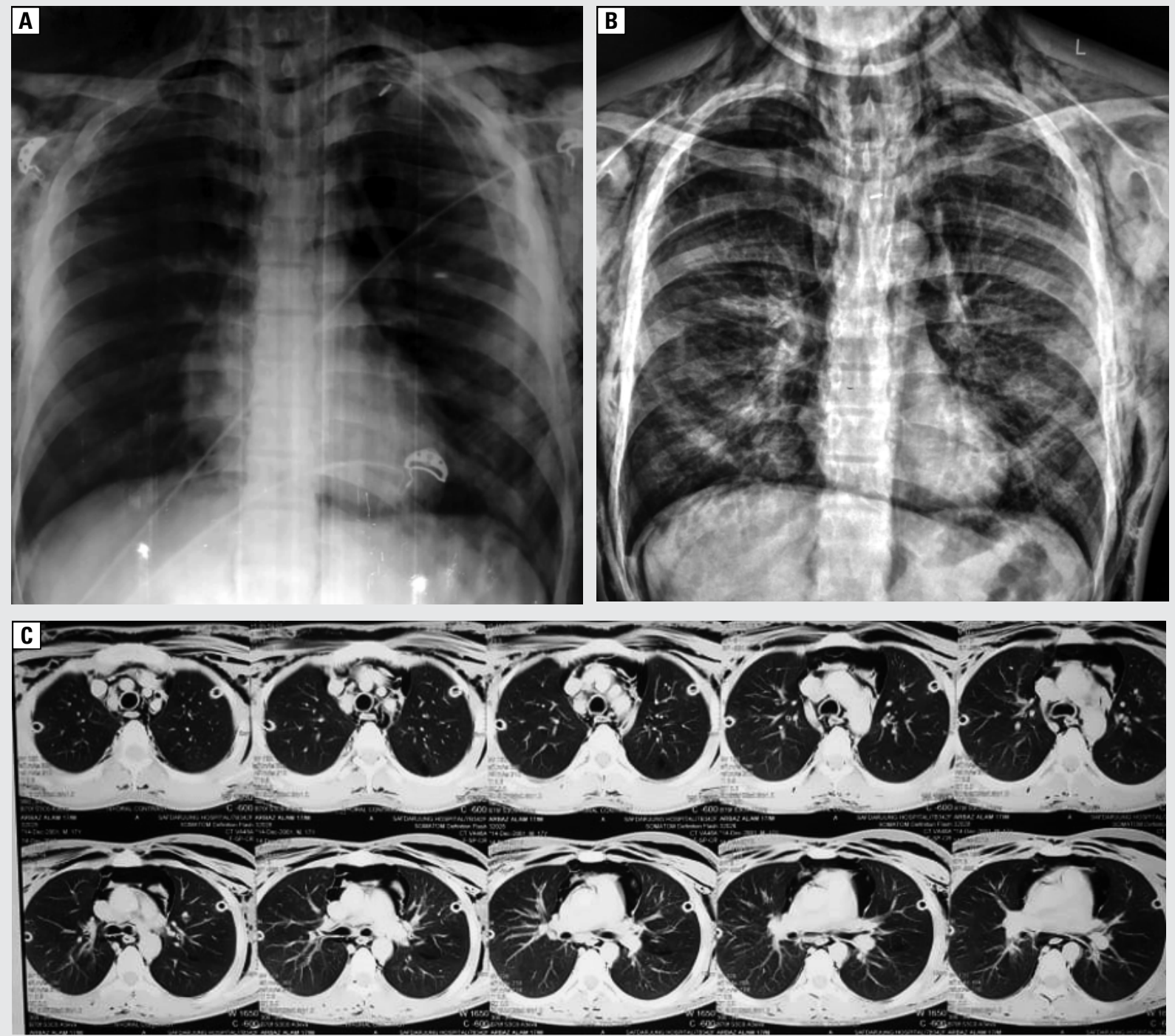

Figure 1. A. CXR - Subcutaneous emphysema, Bilateral Pneumothorax and Pneumomedistinum; B. CXR with bilateral intercostal thoracostomy tube, with tip at the apex and resolution of bilateral pneumothorax; C. CECT chest diffuse subcutaneous emphysema, pneumomediastinum, B/L ICT in situ at apical regions with normal morphology, attenuation and contrast enhancement of B/L lung fields. No cyst, bull or emphysema was observed. Trachea and major bronchus were normal in position, course and calibre. Oesophagus appeared normal in calibre and outline

\section{References:}

1. Currie GP, Alluri R, Christie GL, et al. Pneumothorax: an update. Postgrad Med J. 2007; 83(981): 461-465, doi: 10.1136/ pgmj.2007.056978, indexed in Pubmed: 17621614

2. Trowbridge M. Spontaneous pneumothorax complicating bronchial asthma. Archives of Internal Medicine. 1944; 73(6): 460, doi: 10.1001/archinte.1944.00210180032004.

3. Swain DG. Pneumothorax in acute asthma. Br Med J (Clin Res Ed). 1984; 289(6437): 109, doi: 10.1136/bmj.289.6437.109, indexed in Pubmed: 6428675.

4. Gourdon C, Dietemann A, Beigelman C, et al. Recurrent interlobar pneumothorax in an asthmatic patient. Eur Respir J. 1993; 6(5): 748-749, indexed in Pubmed: 8519387.

5. Ikeda Y, Yamashita H, Tamura T. Diffuse pulmonary ossification and recurrent spontaneous pneumothorax in a patient with bronchial asthma. Respir Med. 1998; 92(6): 887-889, indexed in Pubmed: 9850379.

6. D’Urzo AD, D’Urzo DK, Chapman KR. Case report: pneumothorax and asthma. Can Fam Physician. 1999; 45: 1524-1525, indexed in Pubmed: 10386217.

7. Williams EW, Hart N, Maycock C, et al. Simultaneous spontaneous bilateral pneumothoraces in an asthmatic. West Indian Med J. 2008; 57(5): 508-510, indexed in Pubmed: 19565985.

8. Chau VW, Patel P, Meghjee SPL. Simultaneous bilateral spontaneous pneumothoraces in a patient with occupational asthma. BMJ Case Rep. 2013; 2013, doi: 10.1136/bcr-2013-200080, indexed in Pubmed: 24000212.

9. Khan WA, Curl-Roper T, Helm J, et al. Simultaneous bilateral spontaneous pneumothoraces: a case of occupational asthma. BMJ Case Rep. 2013; 2013, doi: 10.1136/bcr-2013-010057, indexed in Pubmed: 24027249. 
10. Naidoo P. Status asthmaticus with pseudo-dextrocardia, complicated by iatrogenic tension pneumothorax. Pan Afr Med J. 2016; 24 : 31, doi: 10.11604/pamj.2016.24.31.9552, indexed in Pubmed: 27583095.

11. Leo F, Venissac N, Drici MD, et al. Aluminium and primary spontaneous pneumothorax. A suggestive but unconfirmed hypothesis. Interact Cardiovasc Thorac Surg. 2005; 4(1): 21-22, doi: 10.1510/icvts.2004.092312, indexed in Pubmed: 17670347.

12. Moreira MAC, Cardoso A, Silva DG, et al. Hard metal pneumoconiosis with spontaneous bilateral pneumothorax. J Bras Pneumol. 2010; 36(1): 148-151, doi: 10.1590/s1806-37132010000100020, indexed in Pubmed: 20209319.

13. Onyeka WO, Booth SJ. Boerhaave's syndrome presenting as tension pneumothorax. J Accid Emerg Med. 1999; 16(3): 235-236, doi: 10.1136/emj.16.3.235, indexed in Pubmed: 10353061.

14. Venø S, Eckardt J. Boerhaave's syndrome and tension pneumothorax secondary to Norovirus induced forceful emesis. J Thorac Dis. 2013; 5(2): E38-E40, doi: 10.3978/j.issn.2072-1439.2012.07.11, indexed in Pubmed: 23585955.

15. Menga G, Guillemi MM, Piazza LM, et al. Alpha-1 antitrypsin deficiency and spontaneous pneumothorax: just a coincidence? Genes and Environment. 2017, doi: 10.1183/1393003.congress-2017.pa4461.

16. Chorostowska-Wynimko J, Bakuła A, Kulus M, et al. Standards for diagnosis and care of patients with inherited alpha-1 antitrypsin deficiency Recommendations of the Polish Respiratory Society, Polish Society of Pediatric Pulmonology and Polish Society of Pediatric Gastroenterology. Pneumonol Alergol Pol. 2016; 84(3): 193-202, doi: 10.5603/PiAP.2016.0023, indexed in Pubmed: 27238183.

17. MacDuff A, Arnold A, Harvey J, et al. BTS Pleural Disease Guideline Group. Management of spontaneous pneumothorax: British Thoracic Society Pleural Disease Guideline 2010. Thorax. 2010; 65 Suppl 2: ii18-ii31, doi: 10.1136/thx.2010.136986, indexed in Pubmed: 20696690. 